\title{
Relationship between Early Maladaptive Schema and Internet Addiction: A Cross-Sectional Study
}

\author{
Farzaneh Shajari ${ }^{*}$, Faramarz Sohrabi ${ }^{2}$ and Farhad Jomehri ${ }^{2}$ \\ 'Department of Psychology, Faculty of Psychology and Education, Science and Research Branch, Islamic Azad \\ University, Tehran, Iran; farzaneh.shajari@chmail.ir \\ 2Psychology Department, Allameh Tabataba'i University, Tehran, Iran
}

\begin{abstract}
Over the past decade the concept of Internet Addiction has grown in terms of its acceptance as a legitimate clinical disorder often requiring treatment. Many hospitals and clinics have emerged with outpatient treatment services for Internet Addiction. Most recently, the findings of this research area has led American Psychiatric Association to include the diagnosis of Internet Addiction in the Appendix in the DSM-V. The purpose of the present research was to investigate the relationship between Early Maladaptive Schema and Internet Addiction among students. This research is a crosssectional survey. Statistical population of the study included undergraduate and postgraduate students of Azad University, Science and Research Branch, Tehran. 195 students by using simple sampling method were selected. The Young Schema Questionnaire-Short Form (YSQ-SF) and Generalized Problematic Internet Use Scale (GPIUS) were applied as measuring Instruments. To analyze the data Pearson Correlation and regression method were used. Results indicated that there was a significant relationship between 5 domains of Early Maladaptive Schema and Internet Addiction in students. Also, there was a significant relationship between each 15 dimensions of Early Maladaptive Schema with Internet Addiction. According to research findings, the formatting schema during early years can be strong factor in the tendency to use internet. It is essential that more detailed studies should be carried out in this area, particularly about internet addiction.
\end{abstract}

Keywords: Dimensions of Schema, Early Maladaptive Schema, Internet Addiction, Students

\section{Introduction}

The Internet or the World Wide Web, with its large extent, has turned the world into a small village in which people can communicate with each other using variety of tools regardless of their whereabouts. Internet access is rapidly growing and everyday a large number of people become new users of the Internet. Internet is everywhere, it is found at home, school, and university. Number of the Internet users in 2002 was 665 million in the world. As to Iran, we see slight differences with international statistics so that number of the Internet users in Iran showed 31\% growth between 2000 and 2006 and currently 11.5 million of Iranian population are considered as the Internet users ${ }^{1}$. The Internet is featured with countless attracting features and the possibility to remain unanimous has attracted many youngsters to the Internet. As to Internet addiction, like other types of addiction, individuals who need higher levels of motivation and arousal constitute the more vulnerable group. Such needs can be tracked down to the unpleasant experiences in childhood.

Some experts believe that internet addiction in Iran has become a serious issue and there are notable statistics of overusing the Internet among the youth and the juveniles. Todays, we see people who seek solution to their unsatisfied needs and unmet social/psychological needs on the Internet. It is imperative to study and survey the predictor factors of these problems. Internet addiction

* Author for correspondence 
or behavioral dependence on the Internet, whether it is considered a mental problem or a social issue is a chronic, epidemic, and recurrent phenomenon that is the source of many social, financial, family, physical, and psychological problems ${ }^{2}$.

Widyanto and Griffiths ${ }^{3}$ offered a general definition of this psychological construct as a subset of technology addiction, which encompasses behavioral and nonchemical addiction in man-machine interaction. In terms of the Grohol's stages ${ }^{4}$, the first stage (enchantment and temptation) begins when the individual experiences a new environment or when an experienced user finds a new activity or possibility on the Internet. The first stage is highly addictive. In fact, it extends until the individual enters the second stage, called as disillusion or frustration. At the second stage, the individual feels frustrated and not interested in the activity; this stage is followed by the third stage which is reaching a balance. Stage three begins when the individual reaches balance, the distinguishing feature of this stage is that the individual starts to use the Internet in a normal manner. Individuals are different regarding the time it takes for them to enter this stage ${ }^{4}$. Stabilization at the first stage and experiencing symptoms like those witnessed in drug addiction (i.e. resistance, reluctance symptom, feeling the necessity to use the Internet) in some of the patients have led many researchers to rely on the standards of drug addiction as the standards of internet addiction. However, it did not take too long for the scholars to find that the internet addiction should be considered as an impulse control disorder and the symptoms of which must be organized based on the most similar case of impulse control disorder i.e. gambling addiction ${ }^{5}$.

It was Goldberg" who coined the term "Internet addiction" to refer to obsessive and pathological use the Internet. On the other hand, Young proposed a definition of the Internet-related disorders and Pathological Internet Use (PIU) based in DSM-IV standard. He proposed a diagnostic test with eight Yes/No questions about Internet addiction based on the American Association of Psychology's definition of gambling pathology. He argued that when six items out of eight items fit a respondent, the case is considered as an Internet addict ${ }^{7}$.

One definition of Internet addiction states that it is a mental status in which the individual's emotional, mental, professional, academic, and social status sustain damage due to overuse of the Internet ${ }^{8}$.

Early maladaptive schema is fixed and chronical phenomena ${ }^{9}$ that are mostly formed and developed in childhood ${ }^{10}$. In addition, early maladaptive schema evolves over childhood development stage and they are rooted in ineffective connections with other key members in life ${ }^{11}$. Young ${ }^{9}$ argued that the early maladaptive schema cause personality disorders and evolution. The schema might evolve in early childhood through negative experiences with key characters in one's life ${ }^{12}$

Maladaptive schemas are the cognitive infrastructures that lead to formation ofirrational beliefs. They are featured with cognitive, emotional, and behavioral elements. When they are activated, different levels of emotions are formed and lead to different forms of cognitive mental turbulences such as depression, anxiety, professional disability, malnutrition, interpersonal conflicts, and the like. Maladaptive schemas are not directly responsible for personality disorders; although, they increase one's vulnerability toward disorders.

Throughout man's interaction with cognitive coordination, early maladaptive schema fights for their own survival. Although an individual knows a schema is the source of discomfort, they tend to keep it and feel comfortable when they are satisfied with it. People tend to move toward events that fit their schema, a feature that makes the schema hard to change. Patients take the schema for granted and have no doubt about their authenticity. One result of such viewpoint is that the schema affects processing future experiences. They have profound effect on thought, feeling, behaviors, and the way people interact with others. They lead adulthood life to the childhood's unpleasant situations in a controversial and inevitable way, which in most of the cases result in unpleasant outcomes. Schema domains are classified based on 5 dissatisfied emotional needs, out of which two domains are under focus in this study including disconnection and rejection (abandonment/ instability, mistrust/misbehavior, emotional deprivation, shame/defectiveness, social isolation/alienation) and impaired autonomy and or performance (dependence/incompetence, vulnerability to harm or illness, undeveloped self/enmeshment, failure to achieve $)^{13}$. Moeidfar et al. ${ }^{14}$ concluded that those people who use the Internet as an addict, feel less responsible toward the society and their environment. They tend to be socially isolated and encounter with educational/ professional failure; in addition, they enjoy lower level of social support and feel lower self-value. As the results showed, the Internet addicts feel lower self-value, which leads us to the conclusion that one outcome of Internet 
addiction is low self-value.

Dadfarnia et al. ${ }^{15}$ conducted a study titled "early maladaptive schema in the addict and surveying the mediator effect of control center on childhood maladaptive schema to predict quality of life and happiness and comparing early maladaptive schema in healthy and addict individuals." They found that external focus point of control in childhood schema could be a reliable predictor of quality of life in the two groups and there was significant difference between the early maladaptive schema of healthy and addict individuals.

Kim et al. studied internet addiction and its psychological outcomes and reported no psychological co-symptoms with internet addiction. Their subjects obtained low depression and suicide thoughts scores ${ }^{1}$. Given the inconsistent results of different studies, the present study is an attempt to find academic answer to the question "if the early maladaptive schemas are related to internet addiction?"

\section{Methodology}

The study design is survey and cross-sectional.

\subsection{Study Population, Sample Group and Sampling}

Study population was comprised of the students in University of Science and Research-Tehran Branch, in the first semester of academic year 2011-2012 in Bachelors or Masters' Program. As the statistics by the staff department indicated, 29212 individuals comprised the study population.

The participants were selected through random sampling and sample group size $(\mathrm{n}=195)$ was determined based on Cochran's Table with confidence level of 95\%, sampling error of 0.07 , and highest variance level.

Demographical information of the sample group including gender, education level, and age showed that $45 \%$ of the participants were men and $55 \%$ were women; the largest age group was $41 \%$ at age range $25-29 ; 33 \%$ were in bachelors' program and $67 \%$ were in masters' program. Therefore, the majority of the participants were women, at age range 25-29, and in master's program.
Table 1. Frequency and frequency percentage of demographical specifications

\begin{tabular}{lcccc}
\hline Mode & $\%$ & N & $\begin{array}{c}\text { Sub- } \\
\text { groups }\end{array}$ & $\begin{array}{c}\text { Personal/Social } \\
\text { Specifications }\end{array}$ \\
\hline Female & 54.9 & 107 & $\begin{array}{c}\text { Female } \\
\text { Male }\end{array}$ & Gender \\
& 45.1 & & $<24$ & Age \\
$25-29$ & 12.3 & 24 & $25-29$ & \\
& 41.0 & 80 & $30-34$ & \\
& 29.7 & 58 & $34<$ & Program \\
& 16.9 & 33 & Bache- & \\
Masters' & 33.3 & 65 & lors' & \\
& & & Masters' & \\
& 66.7 & 130 & &
\end{tabular}

\section{Research Tools}

\subsection{Generalized Pathological Internet Use Scale (GPIUS)}

The scale is designed by Kaplan based on Davis's theory (2001) on Internet addiction to measure psychological and behavioral specifications of internet addiction. The scale is comprised of 29 statements designed based on Likert's five-point scale (completely disagree $=1, \ldots$, completely agree). It measure negative cognitive and behavioral outcomes of pathological internal use. Reliability of the main form of the question using Cronbach's alpha has been reported between $78 \%$ and $85 \%{ }^{16}$.

Internal consistency index of the questionnaire (i.e. Cronbach's alpha) is $90 \%$, which indicates only $10 \%$ of variance of total point of the questionnaire is contributed by error in measurement. Internal consistency of the scale was obtained using split-half method $(81 \%, \mathrm{P}<0.01)$. Construct validity of GPIUS and its high diagnosing capability are supported and it is used to measure internet addiction in different clinical and normal populations with high validity.

\subsection{Young Schema Questionnaire (YSQ) (Young and Brown, 1990, 2001)}

The questionnaire is a self-statement tool designed to measure the schema with 205 and 75 items in long and short versions respectively (the short form was used in this study). The questionnaire is designed based on 
Likert's six-point scale. Therapists usually assign the patients to fill YSQ at home. The items are arranged based on schema and each item is featured with a two-word code that indicates which schema is measured. Finding two items of one schema with high score is enough to confirm the schema.

\subsection{Validity and Reliability of YSQ}

Validity and Reliability of YSQ given that the questionnaire is a standard questionnaire, its reliability can be ensured based on previous studies. Rijkeboer et al. ${ }^{17}$ studied reliability and distinguishing power of YSQ for Dutch population and reported the split-half reliability coefficient between $68-87 \%$ and retest coefficient with 6 weeks interval equal with 835 . The questionnaire is translated into Persian, and its reliability has been supported.

\subsection{Data Analysis}

The collected data was analyzed using descriptive statistics (central tendency and distribution) and inferential statistics (Pearson's correlation and regression).

\section{Findings}

Table 2 and 3 list descriptive findings such as mean, standard deviation, variance, skewness, and kurtosis of internet addiction and the aspects of early maladaptive schema.

\subsection{Hypothesis One}

There is a relationship between early maladaptive schema and internet addiction.

Pearson's correlation test was used to examine the relationship between each aspect of the early maladaptive schema and internet addiction. As the results showed, error-level of each one of the fifteen aspects of the early maladaptive schema pertinent to the Internet schema was less than 0.05 and all the coefficients were positive.

Table 2. Descriptive data of Internet addiction

\begin{tabular}{|c|c|c|c|c|c|c|c|c|}
\hline \multirow{2}{*}{$\begin{array}{l}\text { Research } \\
\text { Variables }\end{array}$} & \multirow[t]{2}{*}{$\mathrm{N}$} & \multirow[t]{2}{*}{ Mean } & \multirow[t]{2}{*}{ SD } & \multirow[t]{2}{*}{ Variance } & \multirow[t]{2}{*}{ Skewness } & \multirow[t]{2}{*}{ Kurtosis } & \multicolumn{2}{|c|}{ Coefficient Divergence } \\
\hline & & & & & & & Skewness & Kurtosis \\
\hline $\begin{array}{l}\text { Internet } \\
\text { addiction }\end{array}$ & 195 & 66.554 & 16.164 & 261.290 & 0.062 & -0.233 & 0.356 & -0.674 \\
\hline
\end{tabular}

Table 3. Aspects of the early maladaptive schema

\begin{tabular}{|c|c|c|c|c|c|c|c|c|}
\hline \multirow{2}{*}{$\begin{array}{l}\text { RESEARCH VARI- } \\
\text { ABLES }\end{array}$} & \multirow[t]{2}{*}{$\mathrm{N}$} & \multirow[t]{2}{*}{ MEAN } & \multirow[t]{2}{*}{ SD } & \multirow[t]{2}{*}{ VARIANCE } & \multirow[t]{2}{*}{ SKEWNESS } & \multirow[t]{2}{*}{ KURTOSIS } & \multicolumn{2}{|c|}{ COEFFICIENT DIVERGENCE } \\
\hline & & & & & & & Skewness & Kurtosis \\
\hline Emotional deprivation & 195 & 11.338 & 5.844 & 34.153 & 0.819 & -0.392 & 4.702 & -1.130 \\
\hline Abandonment & 195 & 12.308 & 5.270 & 27.771 & 0.804 & 0.622 & 4.616 & 1.795 \\
\hline Mistrust/misbehavior & 195 & 11.492 & 5.755 & 33.117 & 1.127 & 0.680 & 6.476 & 1.962 \\
\hline Social isolation/alienation & 195 & 10.349 & 4.663 & 21.744 & 0.929 & 0.138 & 5.337 & 0.399 \\
\hline Fault/shame & 195 & 7.718 & 3.379 & 11.420 & 1.904 & 4.790 & 10.935 & 13.827 \\
\hline Failure to achieve & 195 & 8.492 & 4.153 & 17.251 & 1.743 & 3.655 & 10.014 & 10.550 \\
\hline $\begin{array}{l}\text { Dependence/lack of con- } \\
\text { fidence }\end{array}$ & 195 & 8.236 & 3.786 & 14.336 & 1.358 & 1.129 & 7.802 & 3.259 \\
\hline $\begin{array}{l}\text { Vulnerability to harm and } \\
\text { illness }\end{array}$ & 195 & $8 / 662$ & $5 / 285$ & $27 / 936$ & $2 / 062$ & $4 / 199$ & $11 / 844$ & $12 / 121$ \\
\hline Enmeshment & 195 & 11.021 & 5.544 & 30.732 & 0.822 & -0.118 & 4.723 & -0.340 \\
\hline Subjugation & 195 & 10.995 & 5.677 & 32.232 & 1.300 & 1.710 & 7.470 & 4.936 \\
\hline Sacrifice & 195 & 17.779 & 6.398 & 40.936 & -0.081 & -0.790 & -0.463 & -2.279 \\
\hline Emotional inhibition & 195 & 12.862 & 6.356 & 40.398 & 0.857 & -0.043 & 4.925 & -0.125 \\
\hline unrelenting standards & 195 & 19.508 & 6.562 & 43.066 & -0.324 & -0.753 & -1.861 & -2.173 \\
\hline Entitlement & 195 & 16.887 & 6.164 & 37.998 & -0.003 & -0.719 & -0.016 & -2.075 \\
\hline $\begin{array}{l}\text { Insufficient self-control/ } \\
\text { self-discipline }\end{array}$ & 195 & 13.000 & 5.019 & 25.186 & 0.472 & -0.241 & 2.713 & -0.696 \\
\hline
\end{tabular}


Table 4. Correlation coefficients of internet addiction and the aspects of early maladaptive schema

\begin{tabular}{|c|c|c|}
\hline Aspects of the early maladaptive schema & Test Indices & Internet Addiction \\
\hline \multirow[t]{2}{*}{ Emotional deprivation } & Pearson's coeffficient & 0.258 \\
\hline & Sig. level (1) & 0.001 \\
\hline \multirow[t]{2}{*}{ Abandonment } & Pearson's coeffficient & 0.188 \\
\hline & Sig. level (1) & 0.004 \\
\hline \multirow[t]{2}{*}{ Mistrust/misbehavior } & Pearson's coeffficient & 0.165 \\
\hline & Sig. level (1) & 0.011 \\
\hline \multirow[t]{2}{*}{ Social isolation/alienation } & Pearson's coeffficient & 0.305 \\
\hline & Sig. level (1) & 0.001 \\
\hline \multirow[t]{2}{*}{ Fault/shame } & Pearson's coeffficient & 0.356 \\
\hline & Sig. level (1) & 0.001 \\
\hline \multirow[t]{2}{*}{ Failure to achieve } & Pearson's coeffficient & 0.300 \\
\hline & Sig. level (1) & 0.001 \\
\hline \multirow[t]{2}{*}{ Dependence/lack of confidence } & Pearson's coeffficient & 0.258 \\
\hline & Sig. level (1) & 0.001 \\
\hline \multirow[t]{2}{*}{ Vulnerability to harm and illness } & Pearson's coeffficient & 0.369 \\
\hline & Sig. level (1) & 0.001 \\
\hline \multirow[t]{2}{*}{ Enmeshment } & Pearson's coeffficient & 0.254 \\
\hline & Sig. level (1) & 0.001 \\
\hline \multirow[t]{2}{*}{ Subjugation } & Pearson's coeffficient & 0.405 \\
\hline & Sig. level (1) & 0.001 \\
\hline \multirow[t]{2}{*}{ Sacrifice } & Pearson's coeffficient & 0.263 \\
\hline & Sig. level (1) & 0.001 \\
\hline \multirow[t]{2}{*}{ Emotional inhibition } & Pearson's coeffficient & 0.360 \\
\hline & Sig. level (1) & 0.001 \\
\hline \multirow[t]{2}{*}{ unrelenting standards } & Pearson's coeffficient & 0.266 \\
\hline & Sig. level (1) & 0.001 \\
\hline \multirow[t]{2}{*}{ Entitlement } & Pearson's coeffficient & 0.239 \\
\hline & Sig. level (1) & 0.001 \\
\hline \multirow[t]{2}{*}{ Insufficient Self-control/self-discipline } & Pearson's coeffficient & 0.331 \\
\hline & Sig. level (1) & 0.001 \\
\hline
\end{tabular}

Therefore, one may argue that all the fifteen aspects of the early maladaptive schema pertinent to internet addiction are positive and significant (Table 3 ).

\subsection{Hypothesis Two}

There is a relationship between the five domains of the early maladaptive schema and internet addiction

To examine the relationship between the five domains of the early maladaptive schema and internet addiction, Pearson's correlation test was used. The results showed that the relationship between the five domains of the early maladaptive schema and internet addiction is significant and positive $(\mathrm{P}<0.05)$. In addition, the correlation level between "other directedness" and internet addiction was higher than that of other domains of the early maladaptive schema (Table 4).

\section{Discussion and Conclusion}

The relationship between the five domains of the early 
Table 5. Correlation between the five domains of the early maladaptive schema and internet addiction

\begin{tabular}{|c|c|c|c|c|c|c|}
\hline & $\begin{array}{c}\text { Internet } \\
\text { addiction }\end{array}$ & $\begin{array}{c}\text { Disconnec- } \\
\text { tion and } \\
\text { rejection }\end{array}$ & $\begin{array}{c}\text { Impaired } \\
\text { autonomy and } \\
\text { performance }\end{array}$ & $\begin{array}{c}\text { Other } \\
\text { directedness }\end{array}$ & $\begin{array}{l}\text { Over-vigilance/ } \\
\text { inhibition }\end{array}$ & $\begin{array}{c}\text { Impaired } \\
\text { limits }\end{array}$ \\
\hline $\begin{array}{l}\text { Correlation coefficient internet } \\
\text { addiction }\end{array}$ & 1 & 0.355 & 0.406 & 0.440 & 0.401 & 0.334 \\
\hline SD & - & 0.001 & 0.001 & 0.001 & 0.001 & 0.001 \\
\hline $\mathrm{N}$ & 195 & 195 & 195 & 195 & 195 & 195 \\
\hline $\begin{array}{l}\text { Correlation coefficient between } \\
\text { disconnection and rejection }\end{array}$ & 0.355 & 1 & 0.522 & 0.307 & 0.369 & 0.394 \\
\hline SD & 0.001 & - & 0.001 & 0.001 & 0.001 & 0.001 \\
\hline $\mathrm{N}$ & 195 & 195 & 195 & 195 & 195 & 195 \\
\hline $\begin{array}{l}\text { Correlation coefficient of im- } \\
\text { paired performance }\end{array}$ & 0.406 & 0.522 & 1 & 0.448 & 0.307 & 0.283 \\
\hline SD & 0.001 & 0.001 & - & 0.001 & 0.001 & 0.001 \\
\hline $\mathrm{N}$ & 195 & 195 & 195 & 195 & 195 & 195 \\
\hline $\begin{array}{l}\text { Correlation coefficient of other } \\
\text { directedness }\end{array}$ & 0.440 & 0.307 & 0.448 & 1 & 0.480 & 0.418 \\
\hline $\mathrm{SD}$ & 0.001 & 0.001 & 0.001 & - & 0.001 & 0.001 \\
\hline $\mathrm{N}$ & 195 & 195 & 195 & 195 & 195 & 195 \\
\hline $\begin{array}{l}\text { Correlation coefficient of } \\
\text { over-vigilance }\end{array}$ & 0.401 & 0.369 & 0.307 & 0.480 & 1 & 0.360 \\
\hline SD & 0.001 & 0.001 & 0.001 & 0.001 & - & 0.001 \\
\hline $\mathrm{N}$ & 195 & 195 & 195 & 195 & 195 & 195 \\
\hline $\begin{array}{l}\text { Correlation coefficient of im- } \\
\text { paired limits }\end{array}$ & 0.334 & 0.394 & 0.283 & 0.418 & 0.360 & 1 \\
\hline $\mathrm{SD}$ & 0.001 & 0.001 & 0.001 & 0.001 & 0.001 & - \\
\hline $\mathrm{N}$ & 195 & 195 & 195 & 195 & 195 & 195 \\
\hline
\end{tabular}

** Correlation is significant at the 0.01 level (2-tailed)

maladaptive schema and internet addiction was examined. To the best of our knowledge, the present study is the first study on the relationship between the five domains of the early maladaptive schema and internet addiction in Iran and the world. There are studies on the early maladaptive schema and the disorders types I and II and few of them were noted in literature review section. As mentioned, the American Psychology Association is going to add internet addiction in DSM-V annex. The relationship between internet addiction and each one of the aspects of the early maladaptive schema and their five domains, which according to Young are formed as highly stable and resistive structures in childhood and extend throughout the life, and their role in one's life were examined.

\subsection{Hypothesis One}

There is a relationship between the five domains of the early maladaptive schema and internet addiction.

The results showed that all the coefficients of the relationship of the fifteen aspects of the early maladaptive schema and Internet addiction were positive and $\mathrm{P}<0.05$. Therefore, the relationship of each one of the fifteen aspects of the early maladaptive schema and internet addiction were positive and significant. There was no similar study in Iran and other countries to compare the obtained results.

Based on the literature review, our results with respect to hypothesis one are consistent, to some extents, with Dadfarnia et al. ${ }^{15}$ who stated that "external focus point 
of the childhood schema could predict quality of life of healthy and addict individuals and there was significant difference between the two groups." One may conclude that the schema are directly effective on probability of internet addiction since, as the results indicated, the stronger the maladaptive schema, the higher the probability of addiction to drugs, the Internet, or obsessive behaviors. Taking into account the findings of Brummett ${ }^{18}$ on "correlations between anxious attachment, early maladaptive schema, and overcoming self-efficacy and intensity of addiction in hypothetical paths", it is clear that our results are consistent with Brummett ${ }^{18}$ because there was a relationship between the early maladaptive schema and addiction.

\subsection{Hypothesis Two}

There is a relationship between the five domains of the early maladaptive schema and internet addiction.

As the results showed there was a positive and significant $(\mathrm{p}<0.05)$ relationship between internet addiction and the five domains of early maladaptive schema (disconnection and rejection, impaired autonomy and performance, impaired limits, other directedness, over-vigilance/inhibition). Based on correlation level, internet addiction was most affected by other directedness followed by impaired autonomy and performance, overvigilance, disconnection and rejection, and impaired limits). According to the literature review, other directedness includes schema subjugation, sacrifice, and approval seeking. People with this schema seek others' approval, prefer continuous emotional relationship, and avoid taking revenge. People with subjugation schema fear abandonment.

Individuals with schema "sacrifice" show overlap between their schema and the twelve concepts of "pathological dependence". It is notable that internet addiction is a pathological dependence. The overlap can explain the relationship between this schema and the Internet schema. In addition, these individual are characterized with "approval seeking" schema so that their sense of value depends on others' responses. Therefore, these individuals may take any measure to satisfy their needs (fear of abandonment, others' approval, continuous emotional relationship, sense of value induce by others, and so on). Naturally, one of the most accessible and easy solutions is the Internet and these people are fast to adopt it.
Ghasemi et al. ${ }^{19}$ compared the early maladaptive schema in three groups of healthy, addicted to tradition drugs, and addicted to synthesized drugs individuals and concluded that individuals in these three groups are different with respect to the early maladaptive schema, emotional deprivation schema, abandonment/ instability, mistrust/misbehavior, social alienation/ isolation, shame and fault, failure to achieve, dependence/ lack of competence, Vulnerability to harm and illness, undeveloped self/enmeshment, subjugation, emotional inhibition, poor self-discipline/self-control. In addition, the three groups were not different regarding the schema sacrifice, entitlement/grandiosity, and unrelenting standards. In general, their results showed that some of the early maladaptive schema the disconnection and rejection domain in particular can be used as important predictors of drug addiction. Therefore, their results are consistent with our results given the relationships between the domains and some aspects of the early maladaptive schema and "subjugation" in particular.

The fact that the questionnaire used as the research tool is a self-statement questionnaire raises questions about authenticity of the data. To collect more reliable data, other data gathering methods are recommended such as observation, interviewing, and behavioral observations. Future works may devise two groups of the Internet addicts and non-interne addicts and compare form and effects of the early maladaptive schema between the two groups, find probable differences, strength and depth of the schema, the effect of the environment, and their priority.

Researchers in the domains of work and activity personality specifications are recommended to survey personality profile (using reliable tests) and examine the type of relationship between "personality specification" and "Internet addiction" based on schema. Results of such studies may help clarifying what personality types with what schema are more probable to overuse the Internet.

The literature review conformed significant relationship between attachment styles, addiction, and the early maladaptive schema. Therefore, studying attachment style and internet addiction can be a worthy topic for future works. Researchers might survey the early (maladaptive) schema to uncover the relationship between "attachment styles" and "Internet addiction" and type of attachment style is effective on tendency to Internet based on schema. 


\section{References}

1. Alavi Seyed S, Merati M, Janatifard F, Eslami M, Haghighi M. Surveying the relationship between psychological symptoms and internet addiction in students of Isfahan-based universities. Hamedan University of Medical Science. 2010; 2: 57-65.

2. Gonzalez NA. Internet addiction disorder and it's relation to impulse control [MA Dissertation]. USA: College of Psychology, Texas University; 2008. p. 6-25.

3. Widyanto L, Griffiths M. Internet addiction: A critical Review. Journal of Mental Health and Addiction. 2006; 4:3151.

4. Grohol, JM. Internet Addiction Guide. A resource for objective, useful information about Internet addiction, a theorized disorder. Is the Internet Addiction Test valid? PsychCentral.com; 20 Jul 2012. Available from: http://psychcentral.com/netaddiction/

5. Ghasemzadeh L, Sharaie M, Moradi A. Surveying prevalence of Internet addiction and its relationship with isolation and self-confidence among high school students in Tehran city. Education Quarterly. 2007; 89:41-68.

6. Goldberg I. Internet addiction disorder. 1996. Available from: http://sh.st/xoK7A?utm_source=scholar.google. com\&utm_medium $=$ QL\&utm_name $=1$

7. Young KS, Abreu NDC. A Handbook and Guide to Evaluation and Treatment Internet Addiction. Hoboken, New Jersey: John Wiley and Sons, Inc.,; 2011.

8. Byun S, Ruffini C, Mills JE, Douglas AC, Niang M, Stepchenkova S, Lee SK, Loutfi J, Lee JK, Atallah M, Blanton M. Internet addiction: metasynthesis of 1996-2006 quantitative research. CyberPsychology and Behavior. 2009; 12(2):203-7.

9. Young J. Cognitive therapy of personality disorders (schema oriented approach) Translated by Sahebi A and Hamidpour H. Tehran, Iran: Arjmand Publciation; 1990.
10. Young JE, Klosko J, Weishaar ME. Schema therapy practitioners guide. New York: Guilford; 2003. p. 73-5.

11. Pinto-Gouveia J, Castilho P, Galhardo A, Cunha M. Early maladaptive schemas and social phobia. Cognitive Therapy and Research. 2006; 30(5):571-84.

12. Torres C. Early maladaptive schema and cognitive distortion in psychophathy and narcissism [PhD Thesis]. Australia: Australian National University; 2002.

13. Young J. Therapeutic schema, applied guideline for clinical experts. In: Hamidpour H, Andouz Z,Tehran, Iran: Arjmand Publication; 2003.

14. Moiedfar S, Habibpour K, Ganji A. Internet addiction, causes and outcomes among juveniles living in Tehran city. Media Quarterly, Fall; 2007; 3:55-80.

15. Dadfarnia SH, Iezadi Khah Z, Sedifi M, Hatampour R. The maladaptive schema in drug addicts. Contemporary Psychology Special Edition. 2010; 1:325-6.

16. Caplan SE. Problematic Internet use and psychosocial well-being: development of a theory-based cognitive-behavioral measurement instrument. Computers in Human Behavior. 2002; 18(5):553-75.

17. Rijkeboer MM, van den Bergh $H$, van den Bout J Stability and discriminative power of the Young Schema-Questionnaire in a Dutch clinical versus non-clinical population. Journal of Behavior Therapy and Experimental Psychiatry. 2005; 36(2):129-44.

18. Brummett BR. Attachment style, early maladaptive schemas, coping self-efficacy, therapy alliance and their influence on addiction severity in methadone-maintenance treatment. ETD Collection for Fordham University, Paper AAT 3286413. 2007.

19. Ghasemi A, Ahadi H, Borjali A. Comparing early maladaptive schema in three groups of normal, traditional drug addicts, and synthetic drug addicts [MSc Dissertation]. Tehran, Iran: Allameh Tabatabaie University; 2010. 